Thorax (1971), 26, 103.

\title{
A simple technique of anaesthesia for experimental open-heart surgery in the calf
}

\author{
M. P. SINGH, R. L. ELLIOT T, a nd D. G. MELROSE \\ Nuffield Unit of Clinical Physiology and Experimental Surgery, Department of Surgery, \\ Royal Postgraduate Medical School of London, London W.12
}

\begin{abstract}
A safe and simple technique of anaesthesia has been developed for the calf, which is increasingly in demand for experimental testing of prosthetic heart valves and other cardiac devices.

In view of the calf's sensitivity to anaesthetics, a minimal number of short-acting agents was employed. Pulmonary complications, to which the calf is said to be so susceptible, were eliminated by a greater control over the artificial respiration.
\end{abstract}

No deaths occurred due to anaesthesia in 35 calves.

The calf has become increasingly popular in experimental open-heart surgery for testing artificial heart valves and heart substitutes. It withstands cardiopulmonary bypass well and the heart tolerates surgical procedures. However, the calf is sensitive to anaesthetic agents and highly susceptible to pulmonary complications. Tavernor (1960) and Wright and Hall (1961) reported poor toleration to barbiturates. The problems were highlighted by Larson, Moffitt, and McGoon (1963) who reported fatalities on induction with thiopentone sodium and a high incidence of postoperative intrapulmonary haemorrhages and atelectasis. Akutsu, Topaz, Mirkovitch, Panayotopoulos, and Kolff (1964) also observed similar complications due to pulmonary hypertension following artificial heart implants.

Mortality from anaesthetic complications continued to be high. Bonchek, Tatooles, and Braunwald (1967) considered that a high proportion of $21 \%$ mortality in their series was related to anaesthetic complications. Remedies recommended for the prevention of postoperative atelectasis included prolonged mechanical ventilation in the postoperative period (MacFarlane, Robillard, and Blundell, 1967) and a high pressure ventilation during anaesthesia (Donawick, Nara, and Baue, 1969).

We have safely anaesthetized 35 calves for cardiopulmonary bypass during valve replacements using a simple technique. Various phases of anaesthesia were managed by manipulating concentrations of halothane (BP) in a mixture of oxygen and nitrous oxide, with occasional supplements of pethidine and methohexitone (Brietal).
High-pressure ventilation was not employed during anaesthesia nor was the mechanical ventilation unduly prolonged in the postoperative period. Pulmonary complications were eliminated by gentle handling of the lungs and by avoiding their overinflation. None of the deaths in the early postoperative period was ascribed to anaesthesia. The technique is described in detail and the advantages are discussed.

\section{THE TECHNIQUE}

PREOPERATIVE PREPARATION Proper selection, carc, and feeding of the calf are important for obtaining successful results. Ruminal tympany could be quite a problem during and after anaesthesia. Thus particular attention was paid to preparation of the rumen. Rigorous fasting, however, was avoided. Solid food was omitted only on the day preceding the operation. Milk feeding was substituted instead, and continued until the evening. Then $5.0 \%$ dextrose water was allowed ad lib until an hour before the operation, when a proprietary 'drench' ${ }^{1}$ was administered. Direct drainage of the rumen was sometimes begun; this is described later,

The calf was then transferred to a holding pen next to the anaesthetic room.

PREMEDICATION Half an hour before the induction the calf was premedicated with Pethilorfan (Roche), $2 \mathrm{mg} / \mathrm{kg}$ of body weight, administered intramuscularly. Atropine sulphate was not administered.

ANAESTHETIC APPARATUS Anaesthetic circuit was prepared before the calf was moved into the anaesthetic

1Suspension of silica in Dimethicone (B.Vet.C.), manufactured by Cooper, McDougall and Robertson, Ltd., Berkhamsted. 
room. The anaesthetic circuit consisted of a Hall's ${ }^{2}$ large size mask which was connected to a Ruben's ${ }^{3}$ non-return valve (Fig. 1) ; the valve in turn was connected to a $60 \mathrm{~cm}$ long corrugated anaesthetic rubber tubing, which led to the anaesthetic machine through a reservoir bag with an expiratory valve for manual control of ventilation.

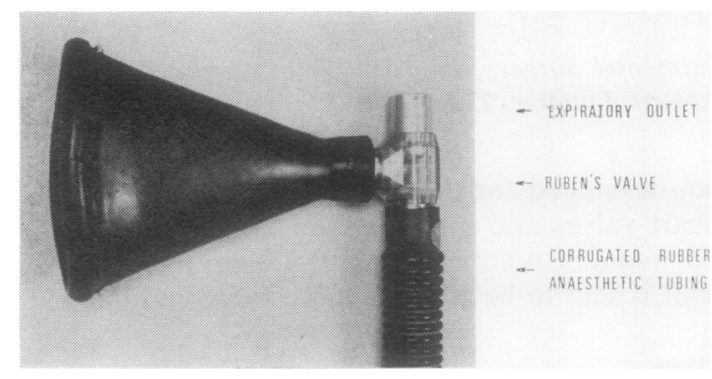

FIG. 1. A large-size Hall's mask for veterinary use. A low-resistance Ruben's valve interposed between the mask and the anaesthetic tubing reduces the dead space.

The anaesthetic machine was constructed in the Experimental Surgical Unit. A Fluotec halothane vaporizer ${ }^{4}$ was provided which could be switched into the circuit. Palmer's Ideal Respirator ${ }^{5}$ was employed for ventilation. A Goldman halothane vaporizer was attached to the inlet of the respirator.

INDUCTION The calf was taken into the anaesthetic room where it was restrained gently. The face mask was applied and fixed firmly to the muzzle with quick release harness (Fig. 2).

The induction was started with a gas mixture o들 oxygen $70.0 \%$ and nitrous oxide $30.0 \%$. Halothane $0.5 \%$ was then added and, as the animal became useß to breathing the mixture, the concentration of halos thane was gradually increased to $4.0 \%$. When the calf sank to its knees it was gently lifted and laid on the operating table, with the operation side uppermost $\vec{\overrightarrow{ }}$ Administration of the anaesthetic gas mixture was continued until the level was deep enough for intubas tion, judged by corneal reflex and depth of respirax tions. The procedure took 7 to 10 minutes.

Intubation Quick intubation was facilitated by the absence of thick and viscid secretions which were prew viously seen in an earlier series when atropine sulf phate was included in the premedication.

A sterile cuffed endotracheal tube designed fo veterinary $^{6}$ use was selected. Sizes V11 and V12 were usually considered suitable, though sizes up to V1 were used at times, according to the size of the calf The tube was lubricated and mounted on a hollow metal tube for ready insertion. The mask was quicklw removed by releasing the retaining harness. The neck was extended; the mouth was opened by pulling the jaws with rubber straps. The tongue was pulled for wards and held on one side. The larynx was locatef with a laryngoscope using a large blade. The mounteg

2Supplied by British Oxygen Company Ltd., London W.6 2Supplied by British Oxygen Company Ltd., London W.6

3Supplied by British Oxygen Company, Ltd., London W.6
4Supplied by Cyprane, Ltd., Keighley, Yorkshire
5Manufactured by C. F. Palmer, Ltd., Effra Road, London S.W 5Manufactured by C. F. Palmer, Ltd., Effra Road, London S.W
6Supplied by the Veterinary Division, British Oxygen Co., Ltd London W.6

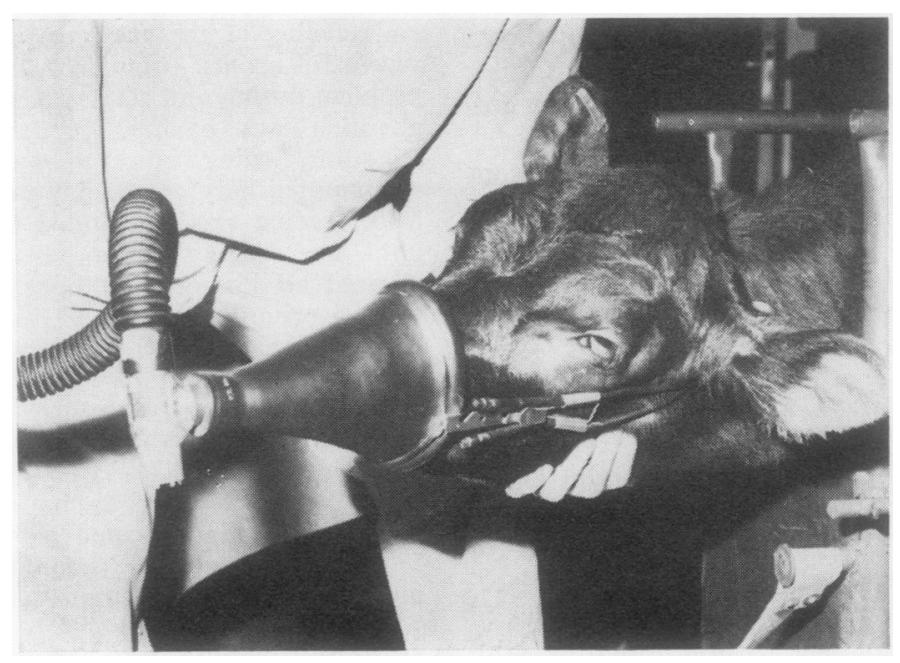

FIG. 2. A calf being induced with Hall's mask attached to the anaesthetic apparatus through a Ruben's valve. A quick release harness holds the mask in firm contact with the muzzle. 


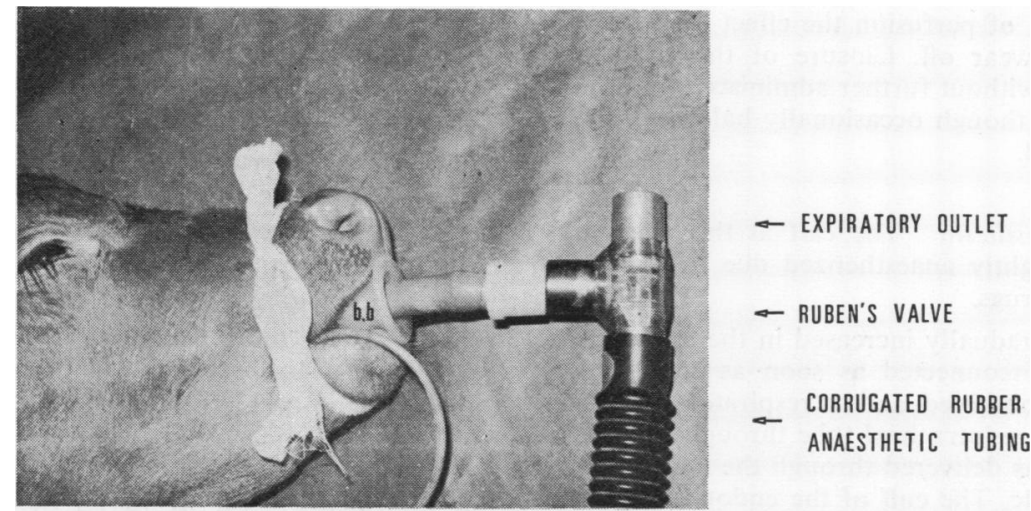

FIG. 3. An anaesthetized calf on spontaneous respiration expires through a Ruben's valve. The endotracheal tube is protected by a bite block (b.b.).

endotracheal tube was then inserted, the cuff inflated, and the metal tube removed.

A large-bore stomach tube was introduced and allowed to drain into a suitable receptacle for gastric decompression. Occasionally, when ruminal tympany was excessive, the rumen was drained directly with a polythene tubing introduced with a trocar and cannula.

A polypropylene 'bite block' (Fig. 3) was slipped over the endotracheal tube and positioned between the teeth to prevent compression of the endotracheal tube. The endotracheal tube was fixed with a bandage. Finally, the anaesthetic circuit was connected to the endotracheal tube with a standard endotracheal mount.

After endotracheal intubation, the concentration of halothane was reduced to 1.5 to $2.0 \%$. Only rarely was it necessary to increase the concentration to $3.0 \%$ during the chest opening.

Ventilation Spontaneous respiration was allowed to continue until just before the chest was opened. The minute volume was measured by attaching a respirometer to the outlet of the Ruben's valve. Thereafter the circuit was connected to the volume cycled Palmer's Ideal Respirator, which was set at a rate of 26-28 cycles/minute. The minute volume of the respirator was adjusted to the value measured during spontaneous respiration. Further adjustments were made if the blood gases measurements showed abnormal values. The ventilation pressure in the circuit did not exceed $10 \mathrm{~cm}$ of water (Fig. 4). During cardiopulmonary bypass the lungs were kept semiinflated with a mixture of oxygen and air, and were intermittently expanded fully by controlled manual compression of the reservoir bag. All visible atelectasis was removed by gentle manual inflation before closure of the chest.

7Made in the Experimental Surgery Unit Workshop of the Royal Postgraduate Medical School, London W.12
Maintenance of anaesthesia At the start of the cardiopulmonary bypass halothane was discontinued ; methohexitone, 1.0 to $1.5 \mathrm{mg} / \mathrm{kg}$ of body weight, and pethidine, 15 to $20 \mathrm{mg}$, were added to the perfusate to prevent reversal of anaesthesia from evaporation of halothane from the oxygenator and dilution effect of the perfusate on circulating through the calf. Anaesthesia was maintained at a light level by adding only small doses of methohexitone sodium, 20 to 30 $\mathrm{mg}$, and pethidine, 10 to $20 \mathrm{mg}$, into the perfusate at about 15 to 20 minute intervals.

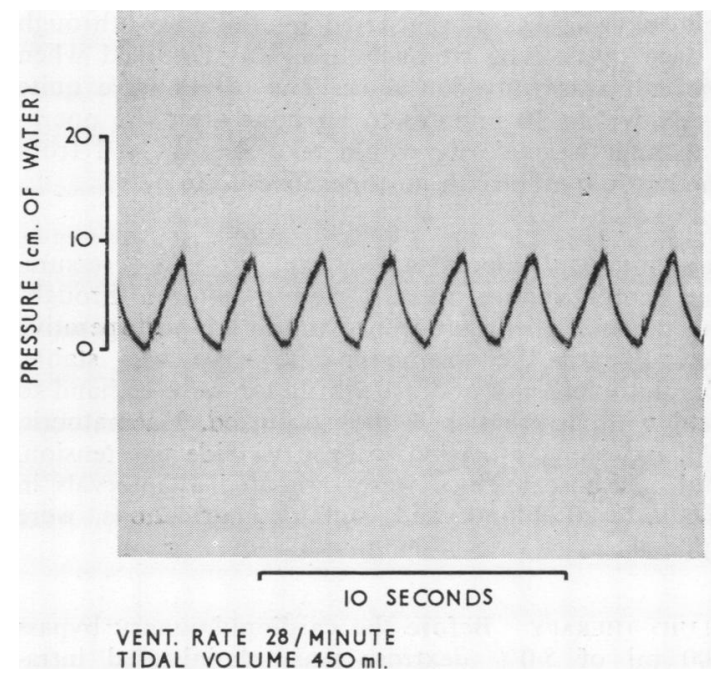

FIG. 4. Pressure recording from the anaesthetic circuit during ventilation with a Palmer's respirator. The pressure did not exceed $10 \mathrm{~cm}$ of water. 
On termination of perfusion the effect of the drugs was allowed to wear off. Closure of the chest was often completed without further administration of any anaesthetic drug, though occasionally halothane $0.5 \%$ was re-introduced.

Reversal of anaesthesia The calf at this stage was generally only lightly anaesthetized due to the effect of the residual drugs.

Air flow was gradually increased in the circuit. The respirator was disconnected as soon as spontaneous respiration was observed and a respiratory bag was connected to the endotracheal tube through a Ruben's valve. Oxygen was delivered through the bag at a rate of 10 litres/minute. The cuff of the endotracheal tube was deflated after clearing the secretions in the oropharynx, so that the air could pass around the tube. Light manual inflation was effected periodically. When the respiratory tidal volume and the minute volume were within normal ranges, the respiratory bag was disconnected intermittently and the calf was allowed spontaneous respiration with air for increasing periods until normal respiration was maintained.

RECOVERY The calf was wheeled on the table into an adjoining recovery room where it was transferred to a sling and nursed in a standing position. On return of the cough reflex, tracheobronchial secretions were cleared and the tube was removed. Analgesia was maintained with intramuscular injections of Pethilorfan (Roche), 25-50 mg. Small and frequent doses were preferred to occasional large ones.

In a majority of the calves oxygenation remained satisfactory while breathing room air. However, in a few, oxygen was administered intermittently through a face mask. The stomach tube was removed when the calf was fully conscious. The calves were quite lively within 30 minutes to an hour after the operation and the majority would take a milk feed from the bottle by the sixth postoperative hour.

MONITORING Electrocardiogram, systemic pressure, and central venous pressure were monitored throughout the anaesthetic procedure and in the postoperative period until the haemodynamic state was stable. Cardiotopic drugs and a defibrillator were at hand to deal with arrythmias if they occurred. Haematocrit, $\mathrm{pH}$, oxygen gas tension, carbon dioxide gas tension, and acid-base balance were estimated at intervals in the arterial blood and suitable corrections were applied.

FLUID THERAPY Before the cardiopulmonary bypass $500 \mathrm{ml}$ of $5.0 \%$ dextrose was administered intravenously. It was continued after the operation until the calf resumed normal drinking and usually one litre was infused. Occasionally blood transfusion was required if the haematocrit was low.

\section{RESULTS}

Thirty-five calves were anaesthetized for card产pulmonary bypass and valve replacement. Their average weight was $48 \mathrm{~kg}$, the youngest weighed $30.2 \mathrm{~kg}$, and the cldest $77.0 \mathrm{~kg}$. Thirty survived the operation and, out of these, four died in early postoperative period. None of these deaths was ascribed to anaesthesia, but death was due to ventricular fibrillation in one, to ruminal tympa in one, and to cerebral air embolus and int thoracic haemorrhage in each of the others. o

On routine necropsy at the end of the experiments, partial collapse and patchy atelectasis \&f the lung were seen in two calves. The changes were due to pleural effusion and did not contribute to their death.

\section{DISCUSSION}

A safe and prolonged anaesthesia is required for cardiopulmonary bypass and open-heart surgical procedures. The technique has been made simple by reducing the number of anaesthetic agents qo $_{0}$ the minımum. The agents employed were short acting and the doses administered were smal, which increased the margin of safety.

Atropine sulphate was eliminated from the pe्टmedication. In an earlier series in this unit it observed that the tracheobronchial secretions be came extremely viscid after administration \&f atropine sulphate and were difficult to remove. Wright and Hall (1961) had also observed simi effects. Furthermore, atropine would have produced tachycardia by vagal inhibition.

On induction with ether a brief period of excitement was seen by Bonchek et al. (1967). Moreover, Akutsu, Mirkovitch, Topaz, and Sen Gupata (1965) noted that induction with ether was sloy. Induction with nembutal was smooth but recovery was prolonged (Hall, 1966). Two deat were reported by Larson et al. (1963) during induction with thiopentone sodium (pentothal). our series, smooth and rapid induction was achieved by gradually increasing the concentris tion of halothane when the calf had become useel to inhaling the lower concentrations and we deqd not encounter excitement during induction.

Wright and Hall (1961) advised against the uकe of muscle relaxants in the calves. However, MacFarlane et al. (1967) induced calves with succiny choline chloride (Scoline). Bonchek et al. (196\%) used it to achieve muscle relaxation during the operations, but they noted that recovery was slow and that it should be discontinued as soon as the chest was closed. We found instead that pethidime 
and methohexitone in small doses produced quite adequate muscle relaxation and narcosis during cardiopulmonary bypass; the recovery from methohexitone was rapid (Hall, 1966) and the effect was not cumulative (Robertshaw, 1964).

The effects of alterations in the concentration of halothane were immediately apparent throughout the various phases of anaesthesia. Hypotension, if produced by halothane, was easily corrected by reducing its concentration in the anaesthetic gas mixture. Thus a greater control was exercised by employing halothane. It should nevertheless be borne in mind, when using halothane with a ventilator in the circuit, that higher concentrations of halothane might be achieved by positive pressure on the vaporizer (Hill and Lowe, 1962). Thus the type of ventilator and its position in the circuit are of considerable importance. The Palmer ventilator is particularly suitable because it has a draw-over system and does not exert positive pressure on the vaporizer. Hallén, Westermark, and Wåhlin (1965) demonstrated that the concentrations delivered from the pump by this method showed mean values about $20 \%$ lower than the preset ones.

To eliminate pulmonary complications, a careful and gentle handling of the lungs is fundamental. Larson et al. (1963) considered that excessively high pressure ventilation in the early experiments in their series produced intrapulmonary haemorrhages. This was also seen by Akutsu et al. (1965) in a calf which developed acute pulmonary hypertension after implantation of a prosthetic heart. We judiciously avoided overdistension of the lungs as the minute-volume delivered by the ventilator did not exceed the minute-volume measured during spontaneous respiration. Furthermore, to avoid postoperative atelectasis the lungs were not allowed to remain collapsed for long periods during cardiopulmonary bypass. Every opportunity was taken to inflate the lungs during the operation, and once again overdistension was avoided. We preferred frequent, manually controlled, gentle inflations to periodic forcible distension.

It may be argued that the simple measures advocated represent no new contribution to the art of animal anaesthesia, and, indeed, it is true that no novel technique nor new drugs are advocated. However, these simple measures and considerable attention to detail have transformed the mortality of complex surgical operations on the calf and provide a safe and reliable anaesthetic technique.

We should like to thank Messrs. F. E. Williams and J. S. Adams and Mrs. J. Becket for technical assistance ; Mr. D. F. Wilson and the staff of the Experimental Surgical Unit animal house for the care of the calves ; Mr. G. Williams for the photographs ; and Miss S. Rankine for secretarial assistance.

\section{REFERENCES}

Akutsu, T., Mirkovitch, V., Topaz, S. R., and Sen Gupta, A. (1965). Insertion of artificial hearts inside the chest of calves. Ann. Surg., 161, 365.

., Topaz, S. R., Mirkovitch, V., Panayotopoulos, E., and Kolff, W. J. (1964). Problems in calf lungs immediately after implantation of an artificial heart. Trans. Amer. Soc. artif. intern. Org., 10, 162.

Bonchek, L. I., Tatooles, C. J., and Braunwald, N. S. (1967). Experimental cardiac surgery in the calf; techniques of anesthesia and operation. Ann. thorac. Surg., 3, 211.

Donawick, W. J., Nara, Y., and Baue, A. E. (1969). Techniques for successful cardiopulmonary bypass in the calf. J. surg. Res., 9, 79.

Hall, L. W. (1966). Wright's Veterinary Anaesthesia and Analgesia, 6th ed. Baillière, Tindall and Cassell, London.

Hallén, B., Westermark, L., and Wählin, Å. (1965). The concentration of halothane with the combined use of Fluotec Vaporizer and Palmer Ventilator for animal experimentation. Acta. anesth. scand., 9, 65.

Hill, D. W. and Lowe, H. J. (1962). Comparison of concentration of halothane in closed and semiclosed circuits during controlled ventilation. Anaes thesiology 23, 291.

Larson, R. E., Moffitt, E. A., and McGoon, D. C. (1963). Experimental cardiac surgery in calves. 1. Anesthesia. J. Surg. Res., 3, 101.

MacFarlane, J. K., Robillard, F. A., and Blundell, P. E. (1967). Anaesthesia for cardiopulmonary bypass in calves. Can. Anaesth. Soc. J., 14, 240.

Robertshaw, D. (1964). Methohexital sodium anaesthesia in calves. Vet. Rec., 76, 357.

Tavernor, W. D. (1960). Anaesthetic procedures in the larger domesticated animals. Proc. roy. Soc. Med., 53, 717.

Wright, J. G., and Hall, L. W. (1961). Veterinary Anaesthesia, 5th ed. Baillière, Tindall and Cox, London. 